\title{
HISTÓRIA DAS POLÍTICAS DE EDUCAÇÃO ESPECIAL NO ESTADO DE ALAGOAS: A IMPORTÂNCIA DA ANÁLISE EM CONTEXTOS SITUADOS
}

\author{
Marilza Pavezi \\ Professora da Universidade Federal de Alagoas - Campus do Sertão (UFAL). Doutora em \\ Educação pela Universidade Estadual de Ponta Grossa (UEPG). E-mail: \\ marilzapavezi2009@ hotmail.com \\ Jefferson Mainardes \\ Professor da Universidade Estadual de Ponta Grossa (UEPG). Doutor em Educação pelo Institute \\ of Education - University of London. E-mail: jefferson.m@uol.com.br
}

\begin{abstract}
RESUMO
O artigo apresenta a história das políticas de Educação Especial no Estado de Alagoas, com ênfase ao contexto social particular no qual essas políticas têm sido colocadas em ação. Esta análise integra uma pesquisa mais ampla sobre a Política de Educação Especial no estado de Alagoas. Conclui-se que a presença do Estado tem sido reduzida no que se refere à garantia das condições mínimas para a atuação das políticas de Educação Especial no Estado de Alagoas, resultando na oferta educacional inadequada do ponto de vista da legislação e limitada do ponto de vista da garantia do acesso dos alunos público-alvo da Educação Especial ao ensino comum e ao Atendimento Educacional Especializado, bem como uma formação incipiente dos agentes envolvidos no processo da Educação Inclusiva.
\end{abstract}

Palavras-chave: Educação Especial. Alagoas. Políticas educacionais.

\section{HISTORY OF SPECIAL EDUCATION POLICIES IN THE STATE OF ALAGOAS: THE IMPORTANCE OF ANALYSIS IN SITUATED CONTEXTS}

\begin{abstract}
The paper presents the history of Special Education policies in the State of Alagoas, Brazil, with emphasis on the particular social context in which these policies have been enacted. This analysis integrates a broader research about Education Policies in Alagoas State (Brazil). It is concluded that the presence of the State has been reduced in terms of guaranteeing the minimum conditions for the enactment of Special Education policies in the State of Alagoas, resulting in inadequate educational provision from the point of view of legislation and limited from the point of view of guaranteeing access to the target population of the Special Education to the common education and the Specialized Educational Service, as well as an incipient education of the agents involved in the process of Inclusive Education.
\end{abstract}

Keywords: Special Education. Alagoas. Education policies.

\section{HISTORIA DE LAS POLÍTICAS DE EDUCACIÓN ESPECIAL EN EL ESTADO DE ALAGOAS: LA IMPORTANCIA DEL ANÁLISIS EN CONTEXTOS SITUADOS}

\section{RESUMEN}

El artículo presenta la historia de las Políticas de Educación Especial en el Estado de Alagoas, con énfasis al contexto social particular en el cual esas políticas han sido puestas en acción. Este análisis integra una investigación más amplia sobre la Política de Educación Especial en el Estado de Alagoas. Se concluye que la presencia del Estado ha sido reducida en lo que se refiere a las garantías de las condiciones mínimas para el desarrollo de las Políticas de Educación Especial en el Estado de Alagoas, resultando una oferta educacional inadecuada desde el punto de vista desde la legislación y limitada desde el punto de vista de la garantía de acceso de los alumnos destinatarios 
de Educación Especial a la enseñanza común y a la Atención Educativa Especializada, como una formación incipiente de agentes involucrados en el proceso de Educación Inclusiva.

Palabras clave: Educación Especial. Alagoas. Políticas Educativas

\section{Introdução}

Este artigo tem como objetivo apresentar a história das políticas de Educação Especial no Estado de Alagoas, de modo a enfatizar o contexto social particular no qual essas políticas são colocadas em ação. Trata-se de uma análise que integra uma pesquisa ampla (PAVEZI, 2018a), que teve como objetivo desvelar as políticas de Educação Especial produzidas e colocadas em ação no Estado de Alagoas, com ênfase no período posterior aos anos de 1990, bem como analisar em que medida a atuação dessas políticas têm garantido o direito à educação para os sujeitos do Público-Alvo da Educação Especial (PAEE). O referencial teórico empregado na citada pesquisa fundamentou-se na abordagem do ciclo de políticas (BOWE; BALL; GOLD, 1992; BALL, 1994; MAINARDES, 2006), na teoria da atuação (BALL; MAGUIRE; BRAUN, 2016) e em conceitos da teoria social de Pierre Bourdieu com destaque aos conceitos de campo, habitus e poder simbólico.

Na referida pesquisa, argumentou-se que as políticas de Educação Especial do Estado de Alagoas tendem a reproduzir as políticas nacionais, resultando em políticas com baixa capacidade de articulação com a realidade do Estado, bem como com as necessidades dos sujeitos. Em decorrência disso e de um conjunto de outras dimensões contextuais, a educação ofertada aos alunos do PAEE, nas escolas das redes públicas de Alagoas, configura-se como um atendimento limitado (com relação ao acesso, à qualidade e às oportunidades de desenvolvimento). Nesse sentido, trata-se de uma oferta educacional que não tem garantido o direito à educação para a totalidade dos sujeitos, dificultando o seu desenvolvimento máximo possível.

Este artigo está dividido em quatro seções. Na primeira, indicamos a importância do contexto na análise de políticas educacionais. Na segunda, caracterizamos o contexto da pesquisa (Estado de Alagoas). Na terceira seção, apresentamos a história das Políticas de Educação Especial em Alagoas e, na última seção, apresentamos as considerações finais.

\section{A importância do contexto}


A teoria da atuação (theory of policy enactment), formulada por Ball, Maguire e Braun (2016), enfatiza a necessidade de levar-se o contexto a sério, de forma a considerar os fatores que influenciam e condicionam o processo de transformação das políticas em ação concreta nos espaços educacionais. Dessa maneira, a retomada da história das políticas educacionais no Estado de Alagoas emergiu como um imperativo para a compreensão da problemática ${ }^{1}$.

No livro Como as escolas fazem as políticas (BALL; MAGUIRE; BRAUN, 2016), Ball e colaboradores apresentam a teoria da atuação (theory of policy enactment). A partir desta teoria, compreende-se que as políticas não são meramente implementadas, mas colocadas em ação com diversas adaptações; ou seja, são interpretadas e traduzidas de formas diversas, de acordo com dimensões contextuais variadas. Isto é possível em razão da existência de certo grau de autonomia no contexto escolar.

Os autores afirmam que "a política é feita pelos e para os professores; eles são atores e sujeitos, sujeitos e objetos da política. A política é inscrita nos corpos e produz posições específicas dos sujeitos.” (BALL; MAGUIRE; BRAUN, 2016, p. 13). Portanto, o conceito assumido pelos autores é o da atuação, em que as políticas são transformadas em ação por meio de processos de interpretação e tradução. O conceito de atuação é utilizado em contraposição à ideia de que as políticas são implementadas, ou meramente implementadas.

Os processos de interpretação e de tradução são distintos, mas interdependentes. A interpretação "é uma leitura inicial, um fazer sentido da política - o que este texto significa para nós? O que nós temos de fazer? Nós temos de fazer alguma coisa?” (BALL; MAGUIRE; BRAUN, 2016, p. 68). As interpretações são elaboradas em reuniões de equipes de liderança, por exemplo, pela equipe da Secretaria de Educação, em que são produzidas formas de apresentação dos objetivos da política, com a finalidade de orientar a prática. Estas interpretações são apresentadas às equipes escolares em reuniões, eventos, ou em forma de textos.

A tradução aproxima-se das linguagens da prática, e

\footnotetext{
${ }^{1}$ A respeito da utilização da abordagem do ciclo de políticas e da teoria da atuação na pesquisa em Políticas Educacionais, ver Mainardes e Gandin (2013a, 2013b); Pavezi (2018b); Lima; Souza e Luce (2018) e Mainardes (2018).
} 
[...] é uma espécie de "terceiro espaço" entre política e prática. É um processo iterativo de fazer textos institucionais e colocar esses textos em ação, literalmente "atuar" sobre a política usando táticas que incluem conversas, reuniões, planos, eventos, 'caminhadas de aprendizagem', bem como a produção de artefatos e empréstimo de ideias e práticas de outras escolas, a compra e a utilização de materiais comerciais e sites oficiais, sendo apoiado por conselheiros da autoridade local (BALL; MAGUIRE; BRAUN, 2016, p. 69-70, grifos dos autores).

No processo de tradução, os agentes escolares dão concreticidade à política, transformando-a em materiais pedagógicos, cartazes, conceitos, orientações, procedimentos, entre outros.

O papel do contexto na atuação da política é analisado por Ball, Maguire e Braun (2016) a partir das seguintes dimensões contextuais:

a) Contextos situados (ex.: localidade, histórias escolares e matrículas);

b) Culturas profissionais (ex.: valores, compromissos e experiências dos professores e "gestão da política" nas escolas);

c) Contextos materiais (ex.: funcionários, orçamentos, edifícios, tecnologia e infraestrutura); e

d) Contextos externos (ex.: grau de qualidade do apoio das autoridades locais; pressões e expectativas de contexto político mais amplo, como classificações do Ofsted ${ }^{2}$, posições na tabela de classificação, requisitos legais e responsabilidades). (BALL; MAGUIRE; BRAUN, 2016, p. 38).

O pesquisador, ao empregar a teoria da atuação, necessita refletir sobre os elementos a serem considerados nas diversas dimensões contextuais. Tomando como objeto as políticas de Educação Especial no Estado de Alagoas (PAVEZI, 2018a), elegemos um conjunto de elementos do contexto da prática a fim de analisar em que medida a atuação destas políticas estava garantindo o direito educacional aos alunos do público-alvo da Educação Especial - PAEE. Para desenvolver este estudo, fez-se necessário explorar o contexto do estado de Alagoas e do Município de Delmiro Gouveia, inclusive sobre a história da Educação Especial naqueles contextos.

\footnotetext{
2 Ofsted (Office for Standards in Education) - Responsável estatal pelos padrões de Educação: é o departamento não ministerial do governo do Reino Unido que define os padrões de qualidade do ensino na Inglaterra. Foi estabelecido em 1993 sob efeito do ato de fundação em 1992.
} 
No desenvolvimento da pesquisa, observou-se que os registros sobre a história da Educação Especial em Alagoas eram bastante restritos. Na revisão de literatura, foram localizados 150 trabalhos sobre Educação Especial em Alagoas, sendo 2 teses, 18 dissertações, 2 livros, 20 capítulos, 17 artigos em periódicos e 91 trabalhos em anais de eventos (PAVEZI, 2018a). Do total de 150, apenas 14 foram incluídos na categoria Inclusão e políticas públicas: uma dissertação (LYKOUROPOULOS, 2007), dois capítulos de livros (BARROS; SIMÕES; FUMES, 2009; FUMES, 2010), dois artigos (BUENO et al., 2005; CALHEIROS; FUMES, 2014) e nove trabalhos completos publicados em anais (FUMES; VILELA, 2014; FUMES, et al., 2013; FUMES; SANTOS, 2013; FIGUEIREDO, 2003; PAVEZI, 2013; PAVEZI; MATIAS, 2014; PAVEZI, 2015; SARMENTO; FUMES, 2009; SILVA, et al., 2013). Os citados trabalhos contemplavam apenas alguns aspectos relacionados à história da Educação Especial em Alagoas.

\section{O Estado de Alagoas: caracterização do contexto situado}

O Estado de Alagoas, representado na Figura 1 que segue, está localizado na região Nordeste do Brasil. Faz divisa com os estados de Pernambuco ao Norte, Sergipe ao Sul, Bahia a Oeste, Oceano Atlântico ao Leste.

Figura 1 - Mapa político-administrativo de Alagoas (2015)

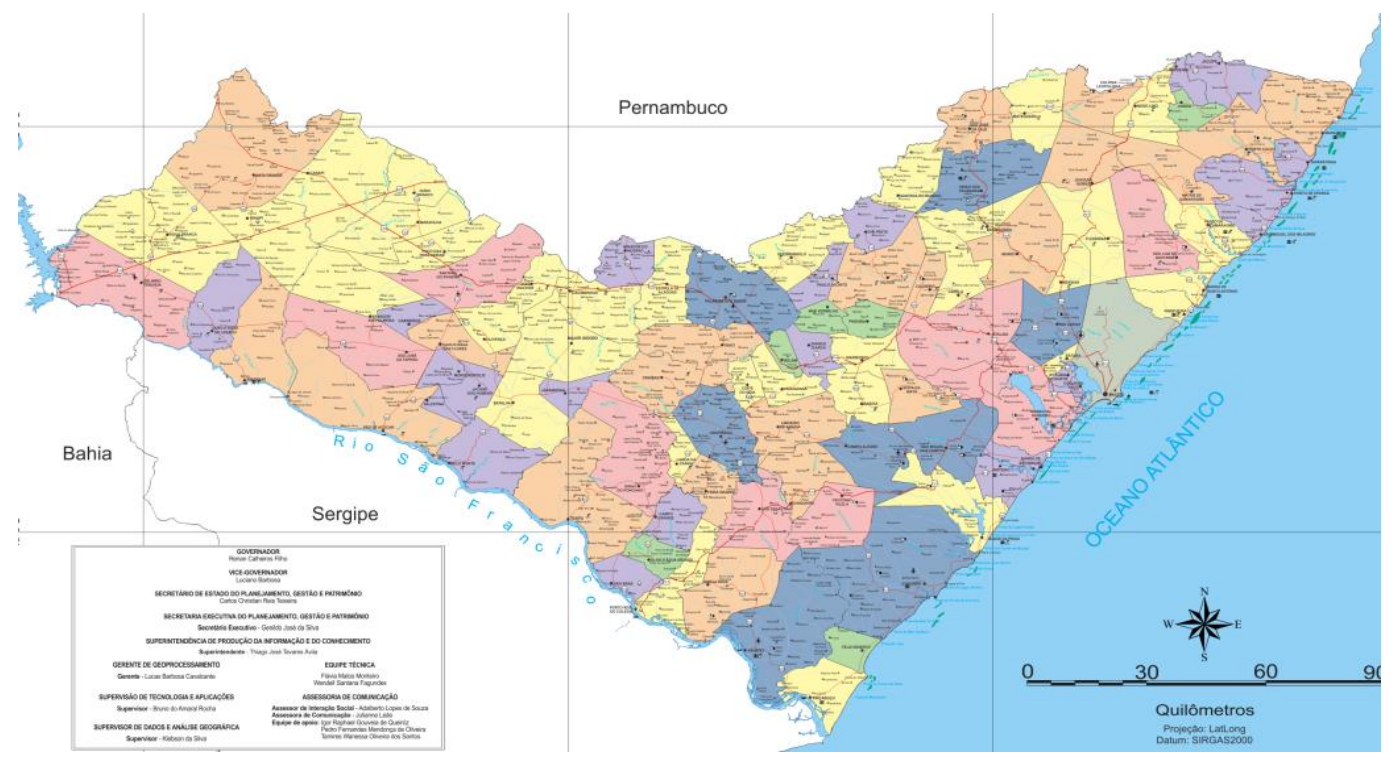

Fonte: Alagoas (2015, n.p.).

De acordo com dados do Instituto Brasileiro de Geografia e Estatística (IBGE, 2017a), o Estado de Alagoas possui uma área de 27.848,003 km² divididos em 102 
municípios. Sua população, em 2010, era de 3.120.494 habitantes com estimativa de 3.375.823 habitantes em 2017. A renda per capita, em 2016, foi de $\mathrm{R} \$ 662,00$. Tem como capital a cidade de Maceió localizada no litoral.

O Estado de Alagoas tornou-se politicamente autônomo a partir de 1817. Emancipou-se da então Capitania de Pernambuco durante a Revolução Pernambucana. Essa Revolução foi um movimento separatista e republicano frustrado pela coroa portuguesa. A antiga comarca de Alagoas manteve-se fiel ao governo imperial. Isso levou D. João VI a proclamar sua emancipação elevando à categoria de província, hoje denominada de Estado (ARAÚJO, 2007).

A origem do Estado de Alagoas, assim como outros estados brasileiros, deu-se a partir das capitanias hereditárias. Nesse sistema, os donatários exerciam total poder sobre o território e as pessoas. Após a Proclamação da República, essa forma de poder manteve-se por meio do coronelismo ${ }^{3}$. Os grandes proprietários de terra tornaram-se os donatários e passaram a exercer o poder e o controle sobre propriedades e pessoas. Para Verçosa (2006), o coronelismo permanece como marca cultural profunda da sociedade alagoana.

A economia alagoana continua sendo essencialmente agrícola. Suas principais atividades econômicas são a cultura canavieira, engenhos e usinas. De acordo com Carvalho (2008), essas atividades representam mais de $90 \%$ na balança comercial e aproximadamente $85 \%$ do emprego industrial. O lento desenvolvimento industrial vem limitando a autonomia econômica do Estado de Alagoas, que mantém certa dependência de programas federais de transferência de renda. Análises desenvolvidas por Andrade et al. (2010) revelam que:

No ano de 2003, Alagoas tinha 57,90\% de seus domicílios considerados pobres, ou seja, com renda domiciliar per capita inferior à linha da pobreza. Além disso, o índice de $\mathrm{Gini}^{4}$ do Estado era de 0,608, o que sinalizava uma alta concentração de renda na região. No entanto, pode-se verificar que, a partir de 2004, esses indicadores vêm gradativamente melhorando mostrando uma redução da pobreza no Estado e uma evolução na distribuição de renda. (ANDRADE et al., 2010, p. 6).

\footnotetext{
${ }^{3} \mathrm{O}$ coronelismo caracteriza-se pela concentração de poder (econômico e político) nas mãos dos grandes fazendeiros, chamados de coronéis, os quais têm ação preponderante na constituição do cenário político. Eles possuem, portanto, poder sobre o Estado.

4 "O Índice de Gini, criado pelo matemático italiano Conrado Gini, é um instrumento para medir o grau de concentração de renda em determinado grupo. Ele aponta a diferença entre os rendimentos dos mais pobres e dos mais ricos." Disponível em: http://www.ipea.gov.br/desafios/index.php?option=com content $\&$ id $=2048$ : catid $=28 \&$ Itemid $=23$. Acesso em: 5 jun. 2017.
} 
Os autores atribuem ao Programa Bolsa Família (PBF) parte da responsabilidade por essa evolução na distribuição de renda em Alagoas (ANDRADE et al., 2010).

De acordo com o Relatório do Bolsa Família e Cadastro Único ${ }^{5}, 634.371$ famílias alagoanas estavam inscritas no Cadastro Único em 2017 (1.819.263 pessoas). No mês de dezembro de 2017, o benefício foi pago a 405.105 dessas famílias. O valor médio do benefício foi de $\mathrm{R} \$ 185,87$, e o valor total transferido pelo Governo Federal chegou a $\mathrm{R} \$$ 75.296.822,00 no mês de dezembro de 2017.

Partindo da estimativa do IBGE que aponta o número de 3.375.823 habitantes no Estado de Alagoas em 2017, as 1.819 .263 pessoas inscritas no Cadastro Único em novembro do mesmo ano correspondem a $53,89 \%$ da população estimada. Isso equivale a 2,87 pessoas por família inscrita (1.819.263 pessoas, dividido por 634.371 famílias). A partir desses cálculos, conclui-se que as 405.105 famílias que receberam o benefício em dezembro de 2017 representam aproximadamente 1.162.651 cidadãos alagoanos (405.105 famílias, multiplicadas por 2,87 pessoas), ou seja, 34,4\% da população. Andrade et al. (2010) argumentam que, para essas famílias, o benefício pode ser a maior ou a única fonte de renda e sobrevivência.

Os cenários, econômico e social, do Estado de Alagoas vêm sendo apontados como fatores de grande interferência na escolarização da população (ALAGOAS, 2006, 2016). De acordo com Nascimento (2014), Alagoas chegou ao século XX com apenas $0,9 \%$ de sua população frequentando a escola. Priorizava-se a oferta de Ensino Médio concentrado na capital do Estado. O sistema educacional expandiu-se em maior volume no Ensino Fundamental chegando a 65\% da oferta total na década de 1990 (ALAGOAS, 2006).

Em 2004, aproximadamente 403 mil adolescentes, entre 12 e 17 anos, pertenciam a famílias com renda per capita inferior a meio salário mínimo, e com pelo menos três anos de defasagem idade-série. Ainda se convivia com a presença de crianças e adolescentes que trabalhavam com jornadas excessivas e péssima remuneração, o que os excluía totalmente do acesso à educação, à cultura e a outros direitos (ALAGOAS, 2006). Embora dados do $\mathrm{IBGE}^{6}$ indiquem que a taxa de trabalho infantil tenha sido reduzida de

\footnotetext{
5 Disponível em: https://aplicacoes.mds.gov.br/sagi/RIv3/geral/relatorio.php\#Cadastro\%20\%C3\%9Anico. Acesso em: 31 jan. 2018.

6 Pesquisa Nacional por Amostra de Domicílios/Cálculos efetuados pela Secretaria de Estado do Planejamento e Desenvolvimento Econômico SEPLANDE/AL que foi unificada à Secretaria de Estado da
} 
12,11\%, em 2007, para 4,35\%, em 2013, o texto do novo Plano Estadual de Educação (PEE/AL) (ALAGOAS, 2016) ainda reconhece a pouca escolarização da população alagoana.

A Pesquisa Nacional por Amostra de Domicílios Contínua (PNADC) de 2016 (IBGE, 2017b) revelou que, entre os jovens de 15 anos ou mais, a taxa de analfabetismo é de $19,4 \%$, e, entre as pessoas com mais de 60 anos, essa taxa é de 46,1\%, sendo uma das mais elevadas do Brasil.

\section{Aspectos históricos das Políticas de Educação Especial em Alagoas}

Até o presente, são bastante restritos os registros históricos das políticas de Educação Especial no Estado de Alagoas. Embora o objetivo desta seção seja apresentar a história das políticas de Educação Especial no Estado de Alagoas, faz-se necessário abordar as principais mudanças nas concepções que embasaram e embasam tais políticas.

Partindo da ideia de que a Educação Especial oferece um atendimento especializado ao seu público-alvo, que se constitui de pessoas com características que as diferenciam das demais, o objetivo da Educação Especial era, inicialmente, promover a normalização, caracterizada pela busca da normalidade pelas pessoas com deficiência. $\mathrm{O}$ intuito era reduzir as diferenças diante do padrão estabelecido socialmente como normal, por intermédio do desenvolvimento de habilidades que evitassem a exclusão e que reinserissem essas pessoas no convívio social. Do ponto de vista de alguns autores, para o sistema educacional, a normalização correspondeu à adequação do aluno às suas estruturas, que se mantiveram inflexíveis (CARVALHO, 2013; KARAGIANNIS; STAINBACK; STAINBACK, 1999).

A discussão sobre a inclusão penetrou o campo educacional a partir da difusão das ideias sobre inclusão social, entendida como o resgate da cidadania com base na democracia e no Estado de Direito (BONETI, 2006). Para responder, na prática, ao movimento mundial pela inclusão social, esperava-se que o campo educacional construísse um sistema educacional único e de qualidade para todos, por meio da reorganização das escolas regulares (MICHELS, 2009; GARCIA, 2004). Um sistema educacional inclusivo, nessa perspectiva, deve promover ação educativa “[...] que proporciona a participação integral da pessoa na sociedade, sobretudo no sentido de fornecer elementos de autonomia 
individual, como é o caso da apropriação aos saberes para o trabalho, aos saberes culturais, da produção da cultura" (BONETI, 2006, p. 118).

A atual Política Nacional de Educação Especial na Perspectiva da Educação Inclusiva (PNEEPEI) orienta a construção do sistema educacional inclusivo, recomendando a reorganização das escolas a fim de atender às especificidades de todos os estudantes. A Educação Especial, nesse sentido, é tida como uma modalidade de ensino que perpassa todos os níveis, etapas e modalidades, realiza o atendimento educacional especializado, disponibiliza os recursos e os serviços e orienta quanto a sua utilização no processo de ensino e aprendizagem nas turmas comuns do ensino regular. As mudanças de concepção da Educação Especial, que partem da normalização, seguem, então, para a integração e avançam para a inclusão, influenciando a definição das políticas de Educação Especial no contexto nacional bem como no Estado de Alagoas.

Para desvelar a história das políticas de Educação Especial em Alagoas, recorremos a documentos (ALAGOAS, 2006, 2016) e sites oficiais (INEP, IBGE, página da SEDUC/AL, Projetos Pedagógicos dos Centros Estaduais de Atendimento Educacional Especializado). Esses documentos mostram ações voltadas ao atendimento daqueles que, atualmente, se convencionou chamar de alunos do Público-alvo da Educação Especial PAEE (BRASIL, 2008).

De acordo com o diagnóstico da Educação Especial no Plano Estadual de Educação (PEE/AL), que esteve vigente até 2015,

[...] o atendimento institucional público às pessoas portadoras de necessidades educacionais especiais somente teve início no ano de 1958, com a oferta de escolarização aos deficientes mentais e, apenas em 1973, é criada, na Secretaria Estadual de Educação, a Diretoria de Educação Especializada, órgão que passou a assumir a coordenação da Educação Especial em Alagoas. (ALAGOAS, 2006, p. 47).

Ressaltamos que, em 1958, a educação das pessoas com necessidades educacionais especiais, na capital alagoana, ocorreu por iniciativa da Associação de Pais e Amigos dos Excepcionais (APAE). Nesse período, as escolas estaduais atendiam apenas a alunos cegos, com bolsa de estudos.

O Quadro 1 que segue apresenta as principais ações voltadas aos alunos do PAEE, a partir da criação da Diretoria de Educação Especializada, em 1973:

Quadro 1 - Ações da Diretoria de Educação Especializada, voltadas aos alunos do PAEE, no âmbito da rede estadual de ensino de Alagoas, a partir de 1973 


\begin{tabular}{|c|c|c|}
\hline ANO & AÇÃO & LOCAL \\
\hline \multirow[t]{4}{*}{1973} & $\begin{array}{l}\text { Atendimento ao aluno com deficiência } \\
\text { visual. }\end{array}$ & $\begin{array}{l}\text { Escola Estadual de Cego Cyro Accioly } \\
\text { (atual Centro Estadual de Atendimento } \\
\text { Educacional Especializado para a } \\
\text { pessoa com Deficiência Visual Cyro } \\
\text { Accioly). }\end{array}$ \\
\hline & $\begin{array}{l}\text { Atendimentos ao aluno com deficiência } \\
\text { auditiva. }\end{array}$ & $\begin{array}{l}\text { Classes especiais de três escolas } \\
\text { estaduais, utilizando-se do método da } \\
\text { oralização. }\end{array}$ \\
\hline & $\begin{array}{l}\text { Atendimento ao aluno com deficiência } \\
\text { mental moderada. }\end{array}$ & $\begin{array}{l}\text { Classes especiais de sete escolas } \\
\text { estaduais. }\end{array}$ \\
\hline & $\begin{array}{l}\text { Atendimento ao aluno com deficiência } \\
\text { mental severa. }\end{array}$ & $\begin{array}{l}\text { Associação de Pais e } \text { Amigos do } \\
\text { Excepcional (APAE); } \\
\text { Associação Pestalozzi; Centro de } \\
\text { Reabilitação de Alagoas (CREAL) e } \\
\text { Centro de Reabilitação Helena } \\
\text { Antipoff. }\end{array}$ \\
\hline 1980 & $\begin{array}{l}\text { Educação profissional com a implantação } \\
\text { da oficina profissionalizante em } \\
\text { marcenaria. }\end{array}$ & $\begin{array}{l}\text { Escola Estadual de Cegos Cyro } \\
\text { Accioly. }\end{array}$ \\
\hline 2001 & $\begin{array}{l}\text { Implantação do processo de Inclusão } \\
\text { Escolar do aluno com deficiência. }\end{array}$ & Escolas das Redes públicas de ensino. \\
\hline 2005 & $\begin{array}{lrrrr}\text { Início da implantação } & \text { de } & \text { salas } & \text { de } \\
\text { Recurso Multifuncionais. } & & & \end{array}$ & Escolas das Redes públicas de ensino. \\
\hline
\end{tabular}

Fonte: Adaptado a partir das informações localizados no site da Secretaria de Estado de Educação e de Esporte de Alagoas (2015). ${ }^{7}$

O avanço na implementação de salas de recursos multifuncionais, em Alagoas, ocorreu conforme mostra a Tabela 1 a seguir:

Tabela 1 - Implementação de Salas de Recursos Multifuncionais, em Alagoas (2005-2011)

\begin{tabular}{lc|r|r|r|r|r|r}
\hline $\begin{array}{l}\text { Ano } \\
\text { Dependência/Tipo V }\end{array}$ & $\mathbf{2 0 0 5}$ & $\mathbf{2 0 0 6}$ & $\mathbf{2 0 0 7}$ & $\mathbf{2 0 0 8}$ & $\mathbf{2 0 0 9}$ & $\mathbf{2 0 1 0}$ & $\mathbf{2 0 1 1}$ \\
\hline Municipal Tipo I & 6 & 8 & 5 & 90 & 190 & 54 & 323 \\
Municipal Tipo II & & & 1 & & 2 & & 18 \\
Estadual Tipo I & & & 2 & 27 & 25 & 1 & \\
Estadual Tipo II & 1 & 1 & 3 & 2 & & \\
Federal Tipo II & & & & & 1 & & \\
Kits de Atualização & & & & & & & 34 \\
TOTAIS & 7 & 8 & 9 & 120 & 220 & 55 & 375 \\
\hline
\end{tabular}

Fonte: Elaborada pelos autores, com dados do $\mathrm{MEC}^{8}, 2005-2011$.

\footnotetext{
${ }^{7}$ A página http://www.educacao.al.gov.br/educacao-basica/educacao-especial/educacao-especial/educacaoespecial-no-sistema-de-ensino-de-alagoas foi excluída do site em 2015. Acesso em: 10 set. 2015.
} 
Ao final de 2011, o Estado de Alagoas contava com 760 salas distribuídas em 97 dos seus 102 municípios, além dos 34 kits de atualização.

A extinção da Gerência de Educação Especial, em agosto de 2015, deu lugar à Supervisão da Educação Especial (SEE). Atualmente, a SEE integra a Superintendência de Políticas Educacionais na nova estrutura da Secretaria de Estado da Educação (SEDUC).

O Estado de Alagoas conta com três Centros Estaduais de Atendimento Educacional Especializado (CEAEE) que colaboram na oferta de atendimento educacional especializado (AEE), localizados em Maceió e vinculados à $1^{\text {a }}$ Gerência Regional de Educação (GERE). O Quadro 2 que segue apresenta as principais informações quanto à criação dos CEAEE e às atividades por eles desenvolvidas.

Quadro 2 - Centros Estaduais de Atendimento Educacional Especializado - CEAEE - Alagoas (2016)

\begin{tabular}{|c|c|}
\hline ficação do CAEE & dades \\
\hline $\begin{array}{l}\text { Centro Estadual de } \\
\text { Atendimento Educacional } \\
\text { Especializado para a pessoa } \\
\text { com Deficiência Visual Cyro } \\
\text { Accioly. }\end{array}$ & $\begin{array}{l}\text { Em 1976, foi instituída a Escola Estadual de Cegos Cyro } \\
\text { Accioly. Atualmente, oferece AEE para alunos com } \\
\text { deficiência visual, atendendo à Resolução CNE/CEB N } \\
04 / 2009 \text {. } \\
\text { Em 2016, foram unificados o Centro Estadual de } \\
\text { Atendimento Educacional Especializado para a Pessoa com } \\
\text { Deficiência Visual Cyro Accioly com o Centro de } \\
\text { Apoio Pedagógico para Atendimento às Pessoas com } \\
\text { Deficiência Visual Erivalda Lima Tavares - CAP, criado em } \\
\text { 2003, ambos em funcionamento no mesmo espaço físico. } \\
\text { De acordo com o diretor, em outubro de 2016, estavam } \\
\text { matriculados } 147 \text { alunos, oriundos de escolas municipais, } \\
\text { estaduais e particulares dos diversos níveis e etapas de } \\
\text { ensino. Oferecem outros serviços de apoio à inclusão além } \\
\text { do AEE e atuam na capacitação de professores que do ensino } \\
\text { regular e de Sala de Recursos Multifuncionais - SRM. }\end{array}$ \\
\hline $\begin{array}{l}\text { Centro de atendimento a } \\
\text { pessoas com surdez-CAS }\end{array}$ & $\begin{array}{l}\text { Criado em agosto de 2006, oferece AEE para alunos com } \\
\text { surdez e deficiência auditiva, incluídos na Educação Básica e } \\
\text { Superior. Oferece diversos serviços de apoio à inclusão, } \\
\text { cursos e oficinas em LIBRAS para pessoas da comunidade, } \\
\text { familiares e para professores que atuam com esses alunos. }\end{array}$ \\
\hline $\begin{array}{l}\text { Centro Estadual de Educação } \\
\text { Especial Professora Wandette } \\
\text { Gomes de Castro }\end{array}$ & $\begin{array}{l}\text { Criado em 1994, inaugurado em } 1996 \text { e redimensionado e } \\
\text { regularizado em 2007. Oferece AEE para pessoas com } \\
\text { necessidades educacionais especiais da rede oficial de ensino } \\
\text { estadual, municipal e oriundas da comunidade, com } \\
\text { deficiência intelectual, múltiplas deficiências, condutas } \\
\text { típicas, síndromes afins, com desordens do espectro autístico, } \\
\text { outros Transtornos do Espectro do Autismo (TEA) e altas } \\
\text { habilidades - superdotação. }\end{array}$ \\
\hline
\end{tabular}

\footnotetext{
${ }^{8}$ Disponível em: http://painel.mec.gov.br/painel/detalhamentoIndicador/detalhes/pais/secid/2. Acesso em: 8 jun. 2015.
} 


\begin{tabular}{|l|l|}
\hline & $\begin{array}{l}\text { Atua na capacitação de professores e coordenadores } \\
\text { pedagógicos com formação continuada na perspectiva da } \\
\text { Educação Inclusiva. }\end{array}$ \\
\hline
\end{tabular}

Fonte: Projetos Político-Pedagógicos dos CEAEE (2016), elaborado pelos autores.

Os serviços oferecidos pelos CEAEE favorecem, prioritariamente, a população da capital, beneficiando poucos alagoanos de municípios próximos e inviabilizando o acesso àqueles que residem muito distante. A SEDUC/AL é mantenedora dos centros; no entanto, a quase totalidade dos seus profissionais é contratada temporariamente. Isso se deve a não criação dos cargos para as funções e atribuições desempenhadas por esses profissionais.

$\mathrm{O}$ alcance do atendimento educacional aos alunos do PAEE pode ser analisado por meio dos dados de matrícula. O site do Instituto Nacional de Estudos e Pesquisas Educacionais Anísio Teixeira (INEP) disponibiliza dados de matrícula a partir de 1997. No entanto, os números referentes à matrícula na Educação Especial aparecem a partir de 1999. Na Tabela 2 que segue, apresentamos os dados de matrícula no período de 1999 a 2017.

Tabela 2 - Dados de matrícula total (Redes: Estadual, municipais e privada) e matrícula na Educação Especial, no Estado de Alagoas (1999-2017)

\begin{tabular}{l|r|r|r}
\hline $\mathbf{A N O}$ & MATRÍCULA TOTAL & $\begin{array}{c}\text { MATRÍCULA } \\
\text { EDUCAÇÃO ESPECIAL }\end{array}$ & \multicolumn{1}{c}{$\%$} \\
\hline $\mathbf{1 9 9 9}$ & 903.729 & 2.139 & 0,24 \\
$\mathbf{2 0 0 0}$ & 940.331 & 1.764 & 0,19 \\
$\mathbf{2 0 0 1}$ & 987.474 & 1.384 & 0,14 \\
$\mathbf{2 0 0 2}$ & 1.003 .817 & 1.657 & 0,16 \\
$\mathbf{2 0 0 3}$ & 1.031 .763 & 1.784 & 0,17 \\
$\mathbf{2 0 0 4}$ & 1.040 .389 & 4.766 & 0,46 \\
$\mathbf{2 0 0 5}$ & 1.044 .827 & 7.770 & 0,74 \\
$\mathbf{2 0 0 6}$ & 1.053 .802 & 5.533 & 0,52 \\
$\mathbf{2 0 0 7}$ & 985.150 & 4.955 & 0,50 \\
$\mathbf{2 0 0 8}$ & 977.272 & 6.682 & 0,68 \\
$\mathbf{2 0 0 9}$ & 981.266 & 7.303 & 0,74 \\
$\mathbf{2 0 1 0}$ & 945.019 & 9.931 & 1,05 \\
$\mathbf{2 0 1 1}$ & 946.614 & 11.786 & 1,24 \\
$\mathbf{2 0 1 2}$ & 921.478 & 13.121 & 1,42 \\
$\mathbf{2 0 1 3}$ & 886.172 & 13.544 & 1,53 \\
$\mathbf{2 0 1 4}$ & 880.923 & 14.452 & 1,64
\end{tabular}




\begin{tabular}{c|r|r|r}
\hline \multicolumn{1}{c|}{ ANO } & MATRÍCULA TOTAL & $\begin{array}{c}\text { MATRÍCULA } \\
\text { EDUCAÇÃO ESPECIAL }\end{array}$ & \multicolumn{1}{c}{$\%$} \\
\hline $\mathbf{2 0 1 5}$ & 947.715 & 15.577 & 1,64 \\
$\mathbf{2 0 1 6}$ & 876.248 & 20.397 & 2,33 \\
$\mathbf{2 0 1 7}$ & 876.351 & 16.833 & 1,92 \\
\hline
\end{tabular}

Fonte: Elaborada pelos autores, com dados do INEP, 1999-2017 (Consulta à matrícula).

Além dos CAEE e das SRM, o Estado de Alagoas conta com outros serviços de apoio à inclusão que não são discutidos neste trabalho, como: a) instituições privadas, com ou sem fins lucrativos, que atuam na oferta do AEE; b) classes hospitalares; e c) atendimento domiciliar. Levantamentos indicam que os serviços em classes hospitalares e o atendimento domiciliar ainda não se encontram devidamente estruturados e em funcionamento no Estado de Alagoas (FONSECA, 2011; SOUZA, 2011).

Com o objetivo de analisarmos se a oferta de atendimento educacional especializado aos alunos do PAEE vem garantindo o direito educacional a toda demanda do estado de Alagoas, levantamos os dados da incidência de deficiência na população mundial, brasileira e alagoana. No Relatório Mundial sobre Deficiência (SÃO PAULO, 2012), a Organização Mundial de Saúde (OMS) aponta um percentual próximo a 15\% da população mundial (estimada em 2010) com alguma forma de deficiência. Com base em resultados de pesquisas mundiais, a OMS apresenta índices entre 2,2 e 3,8\% da população mundial com deficiências mais significativas.

No Brasil, os dados sobre a incidência de deficiência na população são levantados por meio do recenseamento, com aplicação de questionário diretamente aos cidadãos. No entanto, Lenzi (2012) alerta que, embora o Brasil venha adotando um padrão ${ }^{9}$ para o levantamento de dados, baseado na unificação dos conceitos sobre deficiência, os resultados ainda precisam ser analisados ponderadamente. Nesse sentido, optamos por abordar os dados do Censo de 2010, que, de acordo com Lenzi (2012), utilizaram um questionário mais preciso e direto, a fim de estabelecer uma comparação com os dados da OMS. No Censo de 2010, foi apurada a incidência de $32,18 \%$ da população brasileira com

\footnotetext{
${ }^{9}$ As questões aplicadas à população a fim de obter informações sobre a incidência e o grau/nível de deficiência, são elaboradas de forma colaborativa com o Grupo de Washington, o Instituto Brasileiro de Geografia e Estatística (IBGE), o Instituto Nacional de Estadística y Censos (Indec) da Argentina e a Dirección General de Estadística, Encuestas y Censos (DGEEC) do Paraguai. Atuam sob a coordenação do Washington Group on Disability Statistics (GW), com o objetivo de padronizar o levantamento das estatísticas das pessoas com deficiência, tanto nos censos populacionais como em outras pesquisas domiciliares. Disponível em: https://biblioteca.ibge.gov.br/visualizacao/livros/liv95987.pdf. Acesso em: 9 maio 2018.
} 
algum tipo e grau de deficiência. Entretanto, o percentual de pessoas com deficiências declaradas como sendo mais significativas chegou a 8,27\% da população.

A Tabela 3 a seguir indica a incidência de deficiência na população alagoana, com base no Censo de 2010. Elaboramos a tabela utilizando os recursos do Sistema IBGE de Recuperação Automática (SIDRA). Selecionamos as seguintes variáveis: a) população residente — total; b) sexo — total; c) grupo de idade — total; d) ano — 2010; e) situação do domicílio - total.

Tabela 3 - População residente por tipo de deficiência, segundo a situação do domicílio, o sexo e os grupos de idade - Amostra - Características Gerais da População - Alagoas (2010)

\begin{tabular}{|c|c|c|c|c|}
\hline & \multicolumn{4}{|c|}{ NÍVEL OU GRAU DA DEFICIÊNCIA } \\
\hline $\begin{array}{l}\text { DEFICIÊNCIA/ } \\
\% \text { DE INCID. }\end{array}$ & $\begin{array}{c}\text { NẪ } \\
\text { CONSEGUE DE } \\
\text { MODO ALGUM }\end{array}$ & $\begin{array}{c}\text { GRANDE } \\
\text { DIFICULDADE }\end{array}$ & $\begin{array}{c}\text { ALGUMA } \\
\text { DIFICULDADE }\end{array}$ & TOTAL \\
\hline VISUAL & 6.977 & 136.127 & 536.811 & 679.915 \\
\hline$\%$ & 0,22 & 4,36 & 17,20 & 21,78 \\
\hline AUDITIVA & 5.123 & 35.686 & 145.920 & 186.729 \\
\hline$\%$ & 0,16 & 1,14 & 4,68 & 5,98 \\
\hline MOTORA & 11.855 & 84.135 & 173.543 & 269.533 \\
\hline$\%$ & 0,38 & 2,70 & 5,56 & 8,64 \\
\hline $\begin{array}{l}\text { MENTAL/ } \\
\text { INTELECTUAL }\end{array}$ & 59.853 & - & - & 59.853 \\
\hline$\%$ & 1,92 & - & - & 1,92 \\
\hline TOTAL & 83.808 & 255.948 & 856.274 & 1.196 .03 \\
\hline$\%$ & 2,68 & 8,20 & 27,44 & 38,32 \\
\hline
\end{tabular}

Fonte: Elaborada pelos autores, com dados do IBGE (2010)

A população total de Alagoas, em 2010, era de 3.120.494 habitantes. Desse total, $38,32 \%$ da população declarou possuir algum tipo e grau de deficiência. No entanto, interessa-nos analisar a relação entre a oferta da Educação Especial e o percentual declarado de pessoas com maior comprometimento por alguma deficiência, que é de 10,88\%. A Tabela 4 a seguir apresenta esses números e sua relação com os percentuais do Brasil e do mundo de maneira mais clara.

Tabela 4 - Incidência de Deficiência na População Mundial, Brasileira e Alagoana (2010)

\begin{tabular}{l|c|c|c}
\cline { 2 - 4 } \multicolumn{1}{c|}{} & \multicolumn{3}{|c}{ POPULAÇÃO } \\
\hline GRAU/NÍVEL DE DEFICIÊNCIA & MUNDIAL & BRASILEIR & ALAGOANA \\
& & A & \\
\hline ALGUM TIDO DE DEFICIÊNCIA & $15 \%$ & $32,18 \%$ & $38,32 \%$
\end{tabular}


Fonte: Elaborada pelos autores, com dados da OMS (SÃO PAULO, 2012) e do IBGE (2010)

Embora levemos em consideração a dificuldade de uma análise comparativa mais efetiva, esses números reforçam a necessidade de estudos voltados às especificidades das necessidades educacionais desses sujeitos. Com base na análise dos dados de 2010, destacado na Tabela 5, podemos inferir que a oferta de atendimento educacional especializado, no Estado de Alagoas, não vem garantindo o direito à educação para a totalidade dos alunos do PAEE.

Quadro 3 - Dados da população, incidência de deficiência, matrícula total e matrícula na Educação Especial, Estado de Alagoas (2010)

\begin{tabular}{lr}
\hline População do Estado de Alagoas (IBGE, 2010) & 3.120 .494 \\
\hline Incidência de Deficiência mais significativa em Alagoas (IBGE, & $10,88 \%$ \\
\hline Matr) & \\
\hline Matrícula total do Estado de Alagoas (INEP, 2010) & 945.019 \\
\hline Matrícula na Educação Especial em Alagoas (INEP, 2010) & $1,05 \%$
\end{tabular}

Fonte: IBGE (2010), INEP (2010).

\section{Considerações finais}

Neste artigo, apresentamos os principais aspectos históricos das Políticas de Educação Especial do Estado de Alagoas. Destacamos que, em virtude da dificuldade na obtenção de mais dados, há ainda aspectos obscuros que necessitam ser explorados.

A pesquisa sobre a Educação Especial no Estado de Alagoas (PAVEZI, 2018a) evidenciou que as políticas educacionais para a Educação Especial avançaram de forma bastante lenta ao longo do tempo. Além disso, observou-se uma forte tendência de reproduzir e recontextualizar, para o contexto alagoano, as políticas nacionais. A opção pela reprodução/recontextualização de políticas nacionais pode ser considerada limitada, uma vez que nem sempre as políticas nacionais recontextualizadas são capazes de garantir um atendimento mais adequado para as demandas do contexto local. Em decorrência disso e de um conjunto de outras dimensões contextuais, a educação ofertada aos alunos do PAEE, nas escolas das redes públicas de Alagoas, configura-se como um atendimento limitado (com relação ao acesso, à qualidade e às oportunidades de desenvolvimento). Nesse sentido, trata-se de uma oferta educacional que não tem garantido o direito à 
educação para a totalidade dos sujeitos, dificultando o seu desenvolvimento máximo possível.

A presença insuficiente do Estado na garantia das condições mínimas para a atuação das políticas de Educação Especial no Estado de Alagoas reflete-se na oferta educacional inadequada do ponto de vista da legislação, irregular na perspectiva da formação dos agentes e limitada na óptica da garantia do acesso dos alunos do PAEE ao ensino comum e ao Atendimento Educacional Especializado.

Nesse sentido, enfatizamos a importância de explorar contextos situados na pesquisa sobre as políticas de Educação Especial (BALL; MAGUIRE; BRAUN, 2016) e, em particular, a importância de reunir mais dados sobre a história das políticas de Educação Especial em Alagoas.

\section{Referências}

ALAGOAS. Lei $\mathbf{N}^{\mathbf{0}}$ 6.757, 3 de agosto de 2006. Aprova o Plano Estadual de Educação (PEE) para o período de 2006 a 2015. Alagoas: Estado de Alagoas, [2006]. Disponível em: http://www.educacao.al.gov.br/component/jdownloads/send/79-2006/190-file-lei-n-6-757de-03-de-agosto-de-2006. Acesso em: 20 dez. 2018.

ALAGOAS. Alagoas em mapas. Mapa Político-Administrativo 2015. Disponível em: http://dados.al.gov.br/lt/dataset/d8f3ac16-6441-4f45-8c69-

a2fc5a4ff8a6/resource/840632e2-97cc-4e8c-a6f0-

69e929e69c21/download/mapapoliticoadministrativo2015final.png. Acesso em: 30 jan. 2018.

ALAGOAS. Lei $\mathbf{N}^{\mathbf{7}} \mathbf{7 . 7 9 5}$, de 22 de janeiro de 2016. Aprova o Plano Estadual de Educação (PEE). Alagoas: Estado de Alagoas, [2016]. Disponível em: https://sapl.al.al.leg.br/media/sapl/public/normajuridica/2016/1182/1182_texto_integral.pd f. Acesso em: 20 dez. 2018.

ANDRADE, J. A. V. et al. As influências das transferências de renda no Estado de Alagoas: um link entre os principais programas socioeconômicos vigentes. In: CONGRESSO INTERNACIONAL DA REDE MUNDIAL DE RENDA BÁSICA, 13., 2010, São Paulo. Anais eletrônicos [...]. São Paulo: FEA-USP, 2010. Disponível em: http://www.sinteseeventos.com.br/bien/pt/papers/AInfluenciadasTransferenciasdeRendano EstadodeAlagoas.pdf. Acesso em: 20 dez. 2018

ARAÚJO, S. O. S. de. Gestão democrática? Os desafios de uma gestão participativa na educação pública em uma sociedade clientelista e oligárquica. Maceió: EDUFAL, 2007.

BALL, S. J. Education Reform: A critical and post structural approach. Buckingham: Open University Press, 1994.

BALL, S. J.; MAGUIRE, M.; BRAUN, A. Como as escolas fazem as políticas: atuação em escolas secundárias. Ponta Grossa: Editora UEPG, 2016. 
BARROS, M. L. N. L.; SIMOES, N. P. M.; FUMES, N. L. F. A lei orgânica do município de Maceió (1990) e a pessoa com deficiência. In: PRADO, E. C.; ALMEIDA FIGUEIREDO, L. K.; CRUZ NETO, T. L. (Org.). Múltiplos olhares sobre a pesquisa em educação. 1. ed. Maceió: Edufal, 2009. p. 191-204.

BONETI, L. W. Análise crítica dos fundamentos teóricos da educação inclusiva. Revista Diálogo Educacional, Curitiba, v. 6, n. 17, p. 113-124, jan./abr. 2006.

BOWE, R.; BALL, S. J.; GOLD, A. Reforming education \& changing schools: case studies in Policy Sociology. London: Routledge, 1992.

BRASIL. Ministério da Educação. Secretaria de Educação Especial. Política Nacional de Educação Especial na Perspectiva da Educação Inclusiva. Brasília: MEC, 2008.

BUENO, J. G. S. et al. Políticas de educação especial no Brasil: estudo comparado das normas das unidades da federação. Revista Brasileira de Educação Especial, n. 11, p. 97 $118,2005$.

CALHEIROS, D. S.; FUMES, N. L. F. A educação especial em Maceió/Alagoas e a implementação da política do atendimento educacional especializado. Revista Brasileira de Educação Especial, v. 20, n. 2, p. 249-264, jun. 2014.

CARVALHO, C. P. Economia popular: uma via de modernização para Alagoas. 3. ed. Maceió: Edufal, 2008.

CARVALHO, R. E. Educação Inclusiva: com os pingos nos "is". 9. ed. Porto Alegre: Mediação, 2013.

FIGUEIREDO, R. V. As políticas regionais de educação especial no nordeste. In: 26 REUNIÃO ANUAL DA ANPED, 2003, Poços de Caldas. Anais... Poços de Caldas: ANPED, 2003.

FONSECA, E. S. O Brasil e suas escolas hospitalares e domiciliares. In. SCHILKE, A. L.; NUNES, L. B.; AROSA, A. C. (orgs.). Atendimento escolar hospitalar: saberes e fazeres. Niterói: Intertexto, 2011. p. 81-90.

FUMES, N. L. F. Base legal para a inclusão do(a) aluno(a) com deficiência. In: FUMES, N. L. F. (Org.). A inclusão do aluno com deficiência mental na Educação Fundamental. 1. ed. Maceió: Edufal, 2010, v. 1, p. 57-77.

FUMES, N. L. F. et al. A implantação das salas de recursos multifuncionais no município de Maceio/Alagoas: sintetizando os resultados. In: III ENCONTRO DO OBSERVATÓRIO NACIONAL DE EDUCAÇÃO ESPECIAL, 2013, São Paulo, Anais... São Carlos: UFSCAR/ONEESP, 2013. v. 1. p. 1-15.

FUMES, N. L. F.; SANTOS, D. N. Análise da política de implantação das salas de recursos multifuncionais pelas vozes dos professores. In: III ENCONTRO DO OBSERVATÓRIO NACIONAL DE EDUCAÇÃ̃ ESPECIAL, 2013, São Carlos, Anais... São Carlos: UFSCAR/ONEESP, 2013. v. 1. p. 1-11. 
FUMES, N. L. F.; VILELA, C. O. Análise do programa de implantação de sala de recursos multifuncionais da rede municipal de Maceió. In: VI CONGRESSO BRASILEIRO DE EDUCAÇÃO ESPECIAL, 2014, São Carlos. Anais... São Carlos: Galoá, 2014. v. 1. p. 30671-30685.

GARCIA, R. M. C. Políticas públicas de inclusão: uma análise no campo da educação especial brasileira. 2004. 227 f. Tese (Doutorado em Educação) - Universidade Federal de Santa Catarina, Florianópolis, 2004.

IBGE. Instituto Brasileiro de Geografia e Estatística. Alagoas: Panorama. 2017a. Disponível em: https://cidades.ibge.gov.br/brasil/al/panorama. Acesso em: 30 jan. 2018.

IBGE. Instituto Brasileiro de Geografia e Estatística. PNADC - Pesquisa Nacional por Amostra de Domicílios Contínua. 2017b. Disponível em: https://cidades.ibge.gov.br/brasil/al/pesquisa/10070/62922. Acesso em: 30 jan. 2018.

KARAGIANNIS, A.; STAINBACK, S.; STAINBACK, W. Visão geral histórica da inclusão. In: STAINBACK, S.; STAINBACK, W. (Orgs.). Inclusão: um guia para educadores. Porto Alegre: Artes Médicas Sul, 1999. p. 35-47.

LENZI, M. B. Os dados sobre Deficiência nos Censos Demográficos Brasileiro. In: ENCONTRO NACIONAL DOS ESTUDOS POPULACIONAIS - ABEP, 18., 2012, Águas de Lindóia. Anais eletrônicos [...]. Águas de Lindóia: ABEP, 2012. Disponível em: http://www.abep.org.br/publicacoes/index.php/anais/article/view/2041/1999. Acesso em: 20 dez. 2018

LIMA, L. F.; SOUZA, B. S.; LUCE, M. B. A abordagem do ciclo de políticas nos Programas de Pós-Graduação brasileiros: um mapa das teses e dissertações. Revista de Estudios Teóricos y Epistemológicos en Política Educativa, Ponta Grossa, v. 3, p. 1-29, 2018.

LYKOUROPOULOS, C. B. Inclusão escolar de alunos com deficiência: um estudo das propostas e ações políticas e sua apropriação por escolas da rede municipal de ensino de Maceió - AL. 2007. 143 f. Dissertação (Mestrado em Educação: História, Política, Sociedade) - Pontifícia Universidade Católica, São Paulo, 2007.

MAINARDES, J. Abordagem do ciclo de políticas: uma contribuição para a análise de políticas educacionais. Educação \& Sociedade, Campinas, v. 27, n. 94, p. 47-69, jan./abr. 2006.

MAINARDES, J. A abordagem do ciclo de políticas: explorando alguns desafios da sua utilização no campo da Política Educacional. Jornal de Políticas Educacionais, Curitiba, v. 12, n. 16, p. 1-19, 2018.

MAINARDES, J.; GANDIN, L. A. A abordagem do ciclo de políticas como epistemetodologia: usos no Brasil e contribuições para a pesquisa sobre políticas educacionais. In: TELLO, C.; ALMEIDA, M. L. P. (Org.). Estudos epistemológicos no campo da pesquisa em política educacional. Campinas: Mercado de Letras, 2013a. p. 143-167. 
MAINARDES, J.; GANDIN, L. A. Contributions of Stephen J. Ball to the research on educational and curriculum policies in Brazil. London Review of Education, v. 11, n. 3, 256-264. 2013b.

MICHELS, M. H. Paradoxo da formação docente na política de educação inclusiva do Estado de Santa Catarina: a perspectiva clínica como sustentação do trabalho escolar. In: BAPTISTA, C. R.; JESUS, D. M. (Orgs.). Avanços em Políticas de Inclusão: o contexto da educação especial no Brasil e em outros países. Porto Alegre: Mediação, 2009. p. 139152.

NASCIMENTO, E. F. do. Delmiro Gouveia e a Educação na Pedra. Brasília: Senado Federal, Conselho Editorial, 2014.

PAVEZI, M. Implementação da Política Nacional de Educação Especial na perspectiva da educação inclusiva: a distância entre o legal e o real no estado de Alagoas. In: VII SIMPÓSIO INTERNACIONAL "O ESTADO E AS POLÍTICAS EDUCACIONAIS NO TEMPO PRESENTE”, 2013, Uberlândia. Anais... Uberlândia: UFU, 2013.

PAVEZI, M. Programas e ações da Diretoria de Políticas de Educação Especial da SECADI/MEC: levantamentos preliminares de seu alcance no Estado de Alagoas. IN: XIII JORNADA HISTEDBR, 2015, Campinas. Anais... Campinas: HISTEDBR, 2015.

PAVEZI, M. Políticas de Educação Especial no Estado de Alagoas. 2018. 218 f. Tese (Doutorado em Educação) - Universidade Estadual de Ponta Grossa, Ponta Grossa, 2018a.

PAVEZI, M. Contribuições da teoria da atuação: análise a partir de uma pesquisa sobre políticas de Educação Especial no contexto da prática. Revista de Estudios Teóricos y Epistemológicos en Política Educativa, Ponta Grossa, v. 3, p. 1-19, 2018 b.

PAVEZI, M.; MATIAS, T. T. Política de Educação Especial no contexto da educação pública do estado de Alagoas e do Município de Delmiro Gouveia: uma análise inicial. IN: XII JORNADA HISTEDBR, 2014, Caxias. Anais... Caxias: HISTEDBR, 2014. p. 432444.

SÃO PAULO. Relatório mundial sobre a deficiência. World Health Organization, The World Bank. Tradução Lexicus Serviços Lingüísticos. São Paulo: SEDPcD, 2012.

SARMENTO, V. N.; FUMES, N. L. F. O papel das normas de inclusão social e as políticas públicas aplicadas para a formação de docentes de educação física para a efetivação de uma perspectiva da educação inclusiva.. In: ENCONTRO DE PESQUISA EM EDUCAÇÃO DE ALAGOAS, 2009, Maceió. Anais... Maceió: UFAL, Maceió, 2009.

SILVA, L. R. et al. Política para educação inclusiva e formação docente: reflexões de uma pesquisa-ação. In: VI JORNADA INTERNACIONAL DE POLÍTICAS PÚBLICAS (VI JOINPP), 2013, São Luís. Anais... São Luís: UFAL, 2013.

SOUSA, S. S. X. Aprender é vida, ensinar é arte: atendimento pedagógico no setor pediátrico do HUPAA em uma abordagem complexa e multirreferencial. 2011. $204 \mathrm{f}$. Dissertação (Mestrado em Educação Brasileira) - Centro de Educação, Universidade Federal de Alagoas, Maceió, 2011. 
VERÇOSA, É. de G. Cultura e Educação nas Alagoas: História, Histórias. 3. ed. Maceió: AL Educação, 2006.

Recebido em: 11.01 .2019

Aceito em: 28.02.2019 